\title{
'Garcinia Kola Extracts As Antifungal Therapy for Oral Candida Infections'- A Comparative Study
}

\author{
Abah, A. A. ${ }^{1}$, Agbelusi, G. A. ${ }^{2}$, Odukoya, O. A. ${ }^{3}$, Ayanbadejo, P. O. ${ }^{2}$, \\ Adefule-Ositelu, A.O. ${ }^{4}$, Adebiyi K.E. ${ }^{1}$ \\ ${ }^{I}$ Deptartment of Oral Pathology/Oral Medicine, Lagos State University, College of Medicine. \\ ${ }^{2}$ Dept of Preventive Dentistry, Faculty of Dentistry, College of Medicine, University of Lagos (CMUL) \\ ${ }^{3}$ Department of Pharmacognosy, Faculty of Pharmacy, University of Lagos. \\ ${ }^{4}$ Department of Ophthalmology, CMUL.
}

\begin{abstract}
Background: Candida, a normal commensal of the mouth is the cause of candidal infections of the oral cavity in patients with compromised immunity, extremes of ages and in healthy people with local factors that can precipitate the infection.

Objectives: To determine the effect of Garcinia kola (G.kola) extract on oral Candida infection in non- HIV participants, to assess its side effects and to compare its efficacy with Chlorhexidine (CHX) mouthwash.

Materials and methods: A double blinded clinical trial was carried out in non-HIV participants with clinically diagnosed Candida infection. Consecutive patient presenting with oral candidal infection were recruited until the sample size was achieved. They were all screened for varying medical conditions. Garcinia kola extract and chlorhexidine mouthwash were administered to the participants by the research assistant after randomly selected into the two treatment groups. Both the researcher and the participants were blinded..(remove the $2^{\text {nd }}$ full stop)Data generated was analyzed using the statistical Package for Social Sciences for Windows version 16.0, SPSS Inc., Chicago IL.

Results: There were sixty six participants, with thirty three in each group, but fifty-nine completed the study (twenty eight in Garcinia kola group and thirty one in Chlorhexidine group).The lesion was cleared in 96.4\% participants who used Garcinia kola while it was cleared in $80.6 \%$ participants who used chlorhexidine at the end of the $3^{\text {rd }}$ week. There was a statistical significant difference $(p=0.01)$ at the end of the $2^{\text {nd }}$ week in the participants; with 16 (57.1\%) having it cleared with Garcinia kola and 6 (19.4\%) with Chlorhexidine.

Conclusion: Garcinia kola and Chlorhexidine were both effective against candidal infection, but Garcinia kola showed a better clinical outcome.
\end{abstract}

Keywords: Candida, Garcinia kola, Chorhexidine,

\section{Introduction}

Candida albican (italics please) is a normal commensal in the mouth and the oral carriage of the organism is high, with nearly one half of the healthy population harbouring this organism ${ }^{1}$ The organism is the cause of common infections of the oral cavity, oesophagus, skin, gastro-intestinal tract, vagina and vascular system of human '. It can occur in systemic diseases e.g. diabetes mellitus, anaemia, malnutrition, gastrointestinal tract diseases(coelic disease, chron's disease and ulcerative colitis); inhalation of steroids in asthmatic patients, chronic use of antibiotics, chemotherapy, and denture wearing (this was re-phrased)

The current treatments of Candida infection in the oral cavity consist of antifungal drugs such as Nystatin, Miconazole, fluconazole e.t.c. Although these drugs are currently available in the country, many of them have been associated with side effects which include nausea, vomiting, diarrhoea, anorexia, severe allergic reaction e.t.c. All these are known to effect drug compliance. Other mitigating factors include cost and drug resistance. ${ }^{2,3,4}$

Garcinia kola (italics please) belongs to the family of a tropical plant called Guttiferae. It is found in West and Central African sub-regions (Nigeria, Sierra-leone, Ghana, Cameroon and Congo) ${ }^{5}$.The plant has the popular acronym 'wonder plant' among the South Western Nigerian people because every part of it has been found to be of medicinal value ${ }^{6}$. The plant is cultivated for its edible fruits (used as food and tonic). Studies on the fruits of G. kola have resulted in the isolation of the petroleum spirit extract and characterization of kolanone (a novel polyisoprenylated benzophenone). (fullstop)The seeds of Garcinia kola contain several known simple flavonoids together with the biflavonoids (GB-1, GB-1a and GB-2, Garcinal and Garcinoic acid) and amentoflavonone (hydroxybiflavononols presence in the ethyl acetate fraction) ${ }^{7}$. These account for its antifungal, antibacterial and antiviral properties which have been demonstrated in many studies i.e. as antifungal against Candida infection of the eye by Adefule-Ositelu et $\mathrm{al}^{8}$, reduction of intraocular pressure and miosis by 
Adefule-Osditelu et $\mathrm{al}^{9}$; as antibacterial by Adefule-Ositelu ${ }^{10}$ and Sote et $\mathrm{al}^{11}$, as antiviral by Adefule- Ositelu et $\mathrm{al}^{12}$, reducing pain and sub-chondral pressure in knee osteo-arthritis by Adegbehingbe ${ }^{13}$. We therefore set to investigate its antifungal activity against oral Candida and to observe any significant side effects.

Another treatment option for Oral candidiasis is Chlorhexidine (1:6-di-4-chlorphenyl diguanidohexane). It is a broad spectrum antibacterial agent; bacteriostatic at low concentrations and bacteriocidal at high concentrations ${ }^{14}$. It has antifungal properties and it is cheaper than the conventional antifungal drug, hence the preferred choice for comparison with Garcinia kola. The study would therefore be a comparative evaluational study.

\section{Study Design}

\section{Materials And Methods:}

Candida infection.

It was a
infection.

\section{Sample Selection:}

Participants for the study were recruited from the Oral Medicine Clinic of LUTH, Randle General Hospital, Surulere and General Hospital, Lagos Island. In each of the clinics, every consecutive patient presenting with oral candidiasis was recruited until the sample size was achieved.

\section{Consent:}

Written informed consent, were obtained from all the participants before enrollment in the study. A questionnaire was used to collect the data(this statement was re-phrased).

\section{Ethical Clearance:}

Approval for the study was obtained from the Health Research and Ethics committee (HREC) of Lagos University Teaching Hospital (LUTH); Randle General Hospital, Surulere and General Hospital, Lagos Island.

\section{Preparation Of G.Kola Extract}

About 2000g of G.kola nuts were bought from Oyingbo market in Lagos, Nigeria. The plant was identified, authenticated and assigned a voucher specimen number Lagos LUH 3688 which was deposited at the University of Lagos herbarium. A concentration of $30 \%(30 \mathrm{~g}$ in $100 \mathrm{ml}$ ) of G.kola was obtained by cold extraction process which was as close to ordinarily chewing the nut under hygienic condition.

The seed coats on the nuts were scrapped off to expose the white inner parts. These were washed and cut into pieces and blended using Kitchen blender (Binatone). A concentration of 30\% (30g in 100ml) of G.kola was obtained by cold extraction process which was as close to ordinarily chewing the nut under hygienic condition. The water extraction mixture obtained was poured into a beaker and allowed to stand on the bench for 15 hours $^{15}$. It was filtered and the extract (supernatant) was preserved in the refrigerator for the clinical trial.

The concentration of chlorhexidine used was $0.2 \%$.

\section{Data Collection Techniques}

The investigator utilized the service of a research assistant in carrying out the study. The investigator/examiner made the diagnosis of oral candidiasis based on EEC-Clearing House diagnostic criteria 16 .

The participants were screened for HIV infection and all were negative. They were randomly allocated by a trained assistant to two different treatment groups (Garcinia kola extract and Chlorhexidine). This was to ensure that both the participants and the investigator were blinded to the medication each participant was receiving. There were thirty three participants in each group (but 28 and 31 respectively in G.kola and CHX completed the study). The assistant thereafter dispensed the different mouthwashes to the participants according to the group they have been randomly assigned to. Each participant was instructed to use the mouthwash 3 times daily and were advised not to use the mouth rinses within 30minutes of using fluoride containing toothpastes (this is to prevent inactivation of chlorhexidine). The mouth rinses were dispensed in identical containers, labeled A and B. The assistant kept a record of the treatment received by each participant and the investigator was not aware of the participants' treatment groups until after the final treatment outcome was determined. The participants were advised to swish the solution around the mouth and leave for $1 \mathrm{~min}$ before spitting out. The treatments were stopped at the end of the $3^{\text {rd }}$ week. Possible side effects of Garcinia kola was looked for during this study and the examiner did not observe any side effect/s of G.kola and CHX. Participants whose candidal infection did not clear at the end of the third week were placed on regular antifungal drugs. 


\section{Recall Visit}

The participants were seen at one week interval and the clinical state of the oral candidal infection was documented, that is if it had cleared completely, reduced or not. There were 3 recall visits in all.

\section{Clinical Effectiveness}

criteria:

The clinical effectiveness of Garcinia kola extract and chlorhexidine was determined using these

Totally cleared (The lesion completely cleared in the oral cavity).

Partially cleared (the lesion partially cleared in the oral mucosa).

Not cleared (the lesion remained the same).

\section{Results}

A total of 66 participants who were clinical diagnosed with Candida infection were enrolled for the study but 59 participants completed the study and were analysed. The response rate was thus $89.4 \%$

\section{Sex Distribution}

$1.81: 1$

In the study, females were $38(64.4 \%)$ while the males were $21(35.6 \%)$, with female to male ration of

\section{Pattern of(small letter) Age Distribution In The Participants.}

A higher number of the participants 21(35.6\%) were in the $\geq 60$ years age group. The (a space was closed) mean age of the participants was $51.0 \pm 17.5$ years.

Table 2: Age Distribution Of Participants

\begin{tabular}{|c|c|c|}
\hline \multirow[t]{2}{*}{$\begin{array}{l}\text { Age } \\
\text { (year) }\end{array}$} & \multicolumn{2}{|c|}{$\begin{array}{l}\text { HIV negative }(n= \\
\text { 59) }\end{array}$} \\
\hline & Frequenc & $\begin{array}{l}\text { Percen } \\
t\end{array}$ \\
\hline$<20$ & 3 & 5.1 \\
\hline $20-29$ & 3 & 5.1 \\
\hline $30-39$ & 11 & 18.64 \\
\hline $40-49$ & 10 & 16.94 \\
\hline $50-59$ & 11 & 18.64 \\
\hline$\geq 60$ & 21 & 35.59 \\
\hline Total & 59 & 100 \\
\hline $\begin{array}{l}\text { Mean } \\
\text { age }\end{array}$ & \multicolumn{2}{|l|}{$51.0 \pm 17.5$} \\
\hline Median & \multicolumn{2}{|l|}{52} \\
\hline
\end{tabular}

\section{Pattern of Distribution Of The Disease}

Erythematous candidiasis was the most prevalent form seen 32(54.2\%), followed by Pseudomembranous 23(39.0\%). Angular cheilitis was seen in 2(3.4\%) and Pseudomembranous with erythematous occurring together was seen in $2(3.4 \%)$ participants. No case of chronic hyperplastic candidiasis was seen.

\section{Comparison of The Treatment Outcomes Of Garcinia Kola With Chlorhexidine}

In week one, the lesion was not totally cleared in the participants in both groups. In week two, 16 and 6 participants in G.kola and CHX group respectively had it totally cleared while in week three, 27 and 25 participants had it totally cleared in G.kola and CHX group respectively.

There was a statistically significant difference between the G.kola and CHX group in week 2, p $<0.05$. 


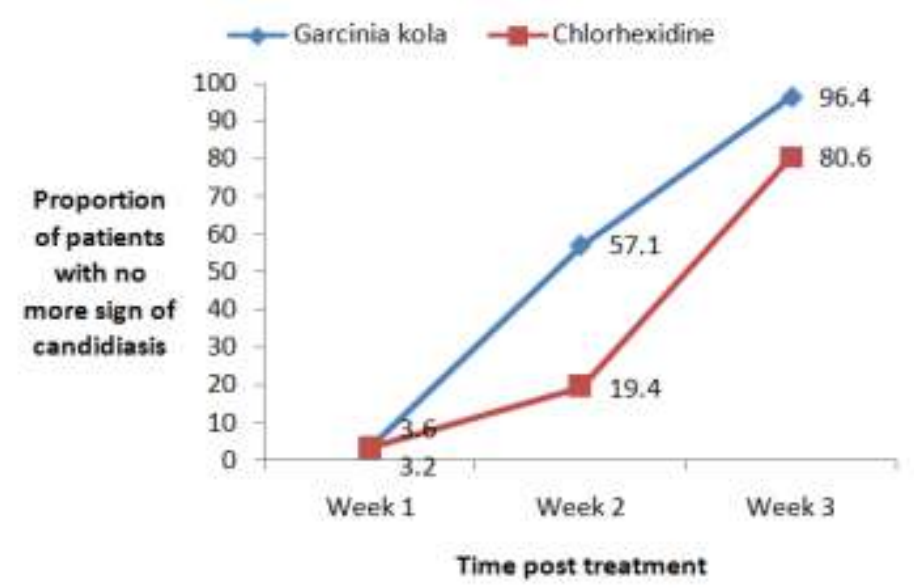

\section{Discussion}

In this present study, females were predominant. This observation was different from the two studies by Kantheti LP et al ${ }^{17}$ where males were more prevalent (Female: Male= 6: 16 and 18:20 respectively).

From the 59 participants seen in the study, Erythematous candidiasis was the most prevalent variant seen; Pseudomembranous was the next variant and angular cheilitis the least seen.

Candida associated denture stomatitis (a form of chronic erythematous candidiasis) affects many denture wearers, about $25-65 \%$. The high incidence of Erythematous candidiasis seen in this study were due to wearing of upper removable partial dentures for extended period of time and lack of regular and proper cleaning of the dentures. Giannini \& Shetty also described Erythematous candidiasis as the most common form of oral candidiasis $^{19}$. The reasons given for this finding were similar to those in our study. Other causes in their study were xerostomia and use of antibiotics.

The antifungal effect of chlorhexidine has been demonstrated in several clinical trials.(fullstop)Chlorhexidine gluconate, $0.2 \%$ solution has been successfully used as a mouth rinse in the treatment of Candida-associated denture stomatitis and in acute pseudomembranous candidiasis, while $2 \%$ suspension was used as an overnight denture disinfectant ${ }^{20,21}$. It has been used successfully in a regimen for the treatment of oral candidiasis in otherwise healthy individuals ${ }^{22,23,24}$. The efficacy of Chorhexidine has also been demonstrated in the elderly patient with oral candidiasis by Persson et al ${ }^{25}$. They observed that there was no statistical difference between Chlorhexidine and Nystatin; further proving its efficacy. Although, its efficacy has been demonstrated, Chlorhexidine exhibits some short comings which are: teeth and mucosal staining, mucosal desquamation and parotid gland enlargement on vigorous rinsing. Also, it is not readily available in an average Nigerian pharmacy shop. The rare availability of Chlorhexidine, and the advantages of Garcinia kola which are affordability, availability, non-toxicity and absence of side effects reported in the literature makes Garcinia kola superior and preferable to chlorhexidine solution.

From the present study, the success rate of Garcinia kola has been demonstrated and this is a major discovery. This study shows the higher efficacy of Garcinia kola as against Chlorhexidine as antifungal therapy coupled with its advantages.

Garcinia kola has been shown to be anti-Candida amongst many other plants like Rubiaceae, Abibacceae, Periplocaceae and Zingiberaceae ${ }^{26}$. Kagbo cited a work by Bohn, where antifungal property of Garcinia kola was demonstrated ${ }^{27}$. A research by Adefule Ositelu demonstrated that Garcinia kola was effective by comparing it with standard anti-microbial agents on common eye fungal and bacterial micro-organisms. These organisms were Candida albicans, Bacillus subtilis, Stapylococcus aureus, Streptococcus pneumonia, Enterococcus faecalis, Escherichia coli, and Klebsiella pyocyannae (italics please) amongst others ${ }^{8}$.

Our study reveals Garcinia kola is a plant with medicinal value. It is cheap, edible, readily available and non-toxic. In this study, no observable side effect was noticed with Garcinia kola, as also reported in other studies ${ }^{13,28}$.

\section{Further Researches}

There is the need for further researches on Garcinia kola and its effect on oral candidal infections. The subjects whose candidal infection did not clear at the end of the third week may be due to the other species of Candida for example Candida glabrata, Candida krusei and Candida topicalis e.t.c. which are more difficult to treat. A biochemical and genetic analysis may be done to identify these species in another study when further 
determining the efficacy of Garcinia kola. This will be more encompassing and contribute to the body of knowledge.

\section{Conclusion}

Garcinia kola and chlorhexidine were both effective against candidal infection, but there was a statistical significant difference between the clinical success rate of Garcinia kola and chlorhexidine at the end of the second week, with Garcinia kola showing a better clinical outcome.

Subjects did not complain of any side-effects of Garcinia kola and none was observed by the investigator during review.

\section{References}

[1]. Lynch DP. Oral candidiasis. History, classification and clinical presentation. Oral Surg-Oral Med-Oral Pathol 1994; 78 (2): 189193.

[2]. Charlier C, Hart E, Lefort A, Ribaud P, Dromer F, Denning DW et al. Fluconazole for the management of invasive candidiasis: where do we stand after 15years? J.Antimicrob chemother. 2006; 57: 384-410.(fullstop)

[3]. Blignaut E, Molepo J, Pujol C, Soll DR, Pfaller MA. Clade-related amphotericin resistance among South African Candida albicans isolates. Diagn. microbiol Infect. Dis. 53:29-31.

[4]. Chen A, Sobel JD. Emerging azole antifungals. Expert Opin. Emerg. Drugs. 2005; 10: 21-33.

[5]. Adedeji OS, Farinu GO, Ameen SA, Olayemi TB. The effects of dietary bitter kola (Garcinia kola) inclusion on body weight, heamatology and survival rate of pullet chicks. J. Anim. Vet. Adv. 2006; 5 (3): 184-187.

[6]. Okojie AK, Ebomoyi MI, Ekhator CN, Emeri CO, Okosun J, Onyesu G, Uhuonrenren O. Review of physiological mechanisms underlying the use of Garcinia kola in the treatment of asthma. The Internet J Pulm Med, 2009; 11 (1): 5.

[7]. Farombi E.O, Owoeye O. Antioxidant and chemopreventive properties of Vernonia amygdalina and Garcinia biflavonoids.Int. J. Environ Res Public Health 2011; 8(6): 2533-2555.

[8]. Adefule-Ositelu A.O, Adefule A.K, Dosa B.O, Onyenefa P.C. Antifungal activities of Garcinia kola extracts on purulent human ocular discharges in Lagos University Teaching Hospital. Nig. Qt. J. Hosp. 2004; 14 (1): 112-114.

[9]. Adefule-Ositelu AO, Onakoya AO, Adefule AK and Dosa BOS. Comparative chromatographic analysis and pharmacodynamic activities of Garcinia kola extracts. Nig. Qt. J. Hosp. Med.2005; 15(1): 30-33.(fullstop)

[10]. Adefule-ositelu AO, Adefule AK, Dosa BOS, and Onyenefa PC. Antibacterial effects of Garcinia kola extracts on ocular bacteria isolates in Lagos, Nigeria. Nig. Qt .J .Hosp. Med. 2004; 14 (1): 266-269.

[11]. Sote EO, Wilson M. The in vitro antibacterial effects of extracts of Nigerian tooth cleaning sticks on periodontopathic bacteria. Afr. Dent. J. 1999; 91: 15-19.

[12]. Adefule Ositelu AO, Adefule AK, Omilabu SA. Clinical Evaluation of Antiviral Effects of Garcinia kola water extract in Epidemic haemorraghic keratoconjunctivis (EHKC) and Epidemic keratoconjunctivitis (EKC) in Lagos. Nig. Qt .J. Hosp. 2004 ; 14 (3-4): 270 276.

[13]. Adegbehingbe OO, Adesanya SA, Idowu TO, Okimi OC, Oyelami OA, Iwalewa EO. Clinical effects of Garcinia kola in knee osteoarthritis. J. Ortho Surg. 2008; 3:34.90

[14]. Hennessey TD. Some Antibacterial properties of chlorhexidine. J Periodontol Res. 1977; 4: 49-65.

[15]. Akerele John O, Osahon, Obasuyi, Maureen, Ebomoyi.I, Isreal, Oboh.E, Osamyi.H, Uwumarongie. Antimicrobial activity of the ethanol extract and fractions of the seed of Garcinia kola Heckel (Guttiferae). Afr J. Biotechnol. 2008; 7 (2):169-172.

[16]. Axell T. et al. An update of the classification and diagnostic criteria of lesions in HIV infection. J Oral Pathol Med 1991; 20(3): 97100 .

[17]. Kantheti LP, Reddy B, Ravikumar S, Anuradha CH, Chandrasekhar P, Rajeswari MR. Isolation, identification and carriage of candida species in PHLAs and their correlation with immunological status in cases with and without HAART. J Oral Maxillofac Pathol. 2012; 16: 38-44.

[18]. Thein ZM, Samaranayake YH, Samaranayake LP. Characteristics of dual species Candida biofilms on (close space) denture acrylic surfaces. Arch Oral Biol.2007; 52: 1200-1208.

[19]. Giannini PJ, Shetty KV. Diagnosis and management of oral candidiasis. Otolaryngol Clin. N. Amer. $2011 ; 44$ (1): $231-240$.

[20]. Arikan A, Kulak Y, Kadir T. Comparison of different treatment methods for localized and generalized simple denture stomatitis. J. Oral Rehab. 1995; 22 (5); 365-369.(fullstop)

[21]. Lal K, Santarpia RP, Pollock JJ. Assessment of anti-microbial treatment of denture stomatitis using an in vivo replica model system: therapeutic efficacy of an oral rinse. J Prosthet Dent. 1992; 67: 72-77.

[22]. Budtz-Jorgensen E \& Loe H. Chlorhexidine as a denture disinfectant in the treatment of denture stomatitis. Scand J Dent Res. 1972; 80: $457-464$.

[23]. Olsen I. Denture stomatitis. The clinical effects of chlorhexidine and amphotericin B. Acta Odontol Scand. $1975 ; 33$ : 47-52.

[24]. Kulak Y, Arikan A, Delibalta N. Comparison of three different treatment methods for generalized denture stomatitis. J Prosthet Dent .1994; 72: 283-288.

[25]. Persson RE, Truelove EL, LeResche L. Therapeutic effects of daily or weekly chlorhexidine rinsing on oral health of a geriatric population. Oral Surg Oral Med Oral Pathol. 1991; 72: 184-191.

[26]. Iwu MW, Duncan AR, Okunji CO. New Antimicrobials of Plant Origin. In. J. Janick (Ed.), Perspective on New crops and new uses. ASHS Press, Alexandria. VA. pp. 457-462.(s)

[27]. Kagbo HD, Ejebe DE. Phytochemistry and preliminary toxicity studies of the methanol extract of the stem bark of Garcinia kola (Heckel). Internet. J. toxicol; 2010: 7 (2)

[28]. Dada AA, Ikuerowo M. Effects of ethanolic extracts of Garcinia kola seeds on growth and heamatology of catfish (Clarias gariepinus) broodstock. Afri J. Agric. Res. 2009; 4(4): 344-347. 